\title{
DESCRIÇÃO DE Syndyas amazonica SP. N., PRIMEIRO REGISTRO DO GÊNERO NA REGIẪO NEOTROPICAL (DIPTERA, EMPIDIDAE, HYBOTINAE)
}

\section{Rosaly ALE-ROCHA ${ }^{1,2}$}

RESUMO - Uma espécie amazônica de Syndyas é descrita e ilustrada: Syndyas amazonica sp.n.. Este é o primeiro registro do gênero na Região Neotropical.

Palavras-chave: Diptera, Empididae, Syndyas, Taxonomia, Distribuição.

Description of Syndyas amazonica sp.n. and the First Record of the Genus in the Neotropical Region (Diptera, Empididae, Hybotinae)

ABSTRACT - One amazonian species of Syndyas is described and illustrated: Syndyas amazonica sp.n.. This is a first geographical record of the genus in the Neotropical Region.

Key words: Diptera, Empididae, Syndyas, Taxonomy, Distribution.

\section{INTRODUÇÃO}

Syndyas Loew é um gênero pequeno da subfamilia Hybotinae (Empididae) cuja distribuição sempre foi considerada incomum pelos autores (Teskey \& Chillcott, 1977). Com 6 espécies na Região Neártica (Teskey \& Chillcott, 1977), 2 na Paleártica (Chavála \& Kovalev, 1988), 14 na Afrotropical (Smith, 1980), 7 na Oriental (Smith, 1977) e 2 na Australiana (Smith, 1989), não tinha registro na região Neotropical.

O gênero é relativamente homogêneo, inclui espécies pequenas ( 2,5 a 3,5 mm de comprimento), castanho-escuras a pretas, reconhecidas pelos seguintes caracteres: olhos holópticos na fronte em machos e fêmeas; probóscide longa e delgada; labelo esclerotinizado, sem pseudotraquéias; palpos delgados, longos, com 1 cerda pré-apical; flagelo oval, pequeno; arista nua, apical; tórax proeminente; asa hialina ou suavemente enfuscada com áreas nuas, sem microtrí- quias; célula cup tão ou mais longa que a $\mathrm{bm}$, com ângulo externo agudo; veia $\mathrm{Sc}$ e $\mathrm{M}$ evanescentes ou ausentes; veia Rs curta atingindo a R1 em ângulo reto; tíbia posterior clavada; primeiro tarsômero posterior curto e dilatado; terminália masculina assimétrica. As espécies neárticas são distinguidas pelo número de séries de cerdas acrosticais, padrão de pruinosidade torácica, distribuição de microtríquias na asa, aspecto das cerdas e tamanho do fêmur posterior.

Os adultos de Syndyas são predadores em ambos os sexos, os olhos holópticos em machos e fêmeas são presumidos serem adaptados para atacar insetos em vôo partindo de baixo para cima; o acasalamento ocorre no substrato, sem alimentação paralela (Chavála, 1983). Estágios imaturos são desconhecidos. Nas zonas temperadas e frias do hemisfério norte os adultos parecem restritos a regiões pantanosas (Chavála, 1983).

\footnotetext{
Instituto Nacional de Pesquisas da Amazônia, Coordenação de Pesquisas em Entomologia, Caixa Postal 478,69011-970 - Manaus, Amazonas, Brasil, alerocha@inpa.gov.br

2 Bolsista do CNPq.
} 


\section{MATERIAL E MÉTODOS}

O material estudado pertence a coleção de invertebrados do Instituto Nacional de Pesquisas da Amazônia (INPA), Manaus, Amazonas, Brasil.

Os termos e estruturas seguem McAlpine (1981) exceto a terminália masculina onde os termos de Cumming et al (1995) foram seguidos.

\section{Syndyas amazonica sp.n.}

Descrição. Holótipo macho. Corpo: $3,0 \mathrm{~mm}$; asa: $2,2 \mathrm{~mm}$.

Cabeça. Facetas superiores discretamente maiores que as inferiores. Antena castanha; flagelo oval, duas vezes mais longo que largo; arista duas vezes e meia o comprimento da antena. Face preta. Peças bucais castanhas. Pós-crânio preto com pruina castanha.

Tórax com pruína castanha exceto por uma faixa brilhante, sem pruina, em forma de meia-lua na porção anterior do escuto; escuto preto, pleuras castanhoescuras. Escuto com cerdas longas, delgadas, amarelas; acrosticais com 4 séries; dorsocentrais unisseriadas; intraalares numerosas e mais longas. Notopleura com 2 cerdas longas, robustas e amarelas. Escutelo com 1 par apical longo, convergente e 3 cerdas laterais delgadas, cerca de $1 / 5$ do comprimento do par apical.

Asa (Fig. 1) hialina, pterostigma ausente. Células costal, r1, br, bm, dois-terços basais da $\mathrm{r} 2+3$, metade basal e margem dorsal da metade distal da cup sem microtriquias. Veia Sc ausente. Célula br mais longa que a bm devido ao deslocamento da veia r$\mathrm{m}$ para mais distante da base da $\mathrm{R} 4+5$.

Pernas pretas exceto a coxa anterior e média, articulação fềmur-tibial e ápice da tibia anterior castanhoclaras, tíbia média e primeiro e segundo tarsômeros de todos os tarsos amarelos. Cerdas amarelas delgadas. Perna posterior (Fig.2): fêmur dilatado; tíbia levemente dilatada em direção ao ápice; primeiro tarsômero curto, discretamente dilatado, com espinhos ventrais claros, um espinho apical curto e preto na face anterior dos tarsômeros 1-3. Cerdas destacadas: tíbia média com algumas cerdas dorsais curtas e robustas e 1 póstero-ventral apical longa; primeiro tarsômero anterior e médio com cerdas dorsais mais longas; primeiro tarsômero médio com 1 cerda póstero-ventral sub-basal robusta; trocanter posterior com 1 espinho ventral curto; fêmur posterior com 1 cerda ânterodorsal no $1 / 3$ distal e face ântero-ventral com série de cerdas espiniformes com bases protuberantes.

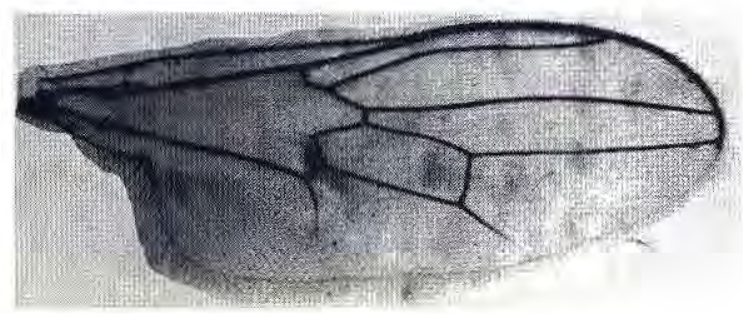

Figura 1. Syndyas amazonica sp.n. Holótipo macho. Asa. 

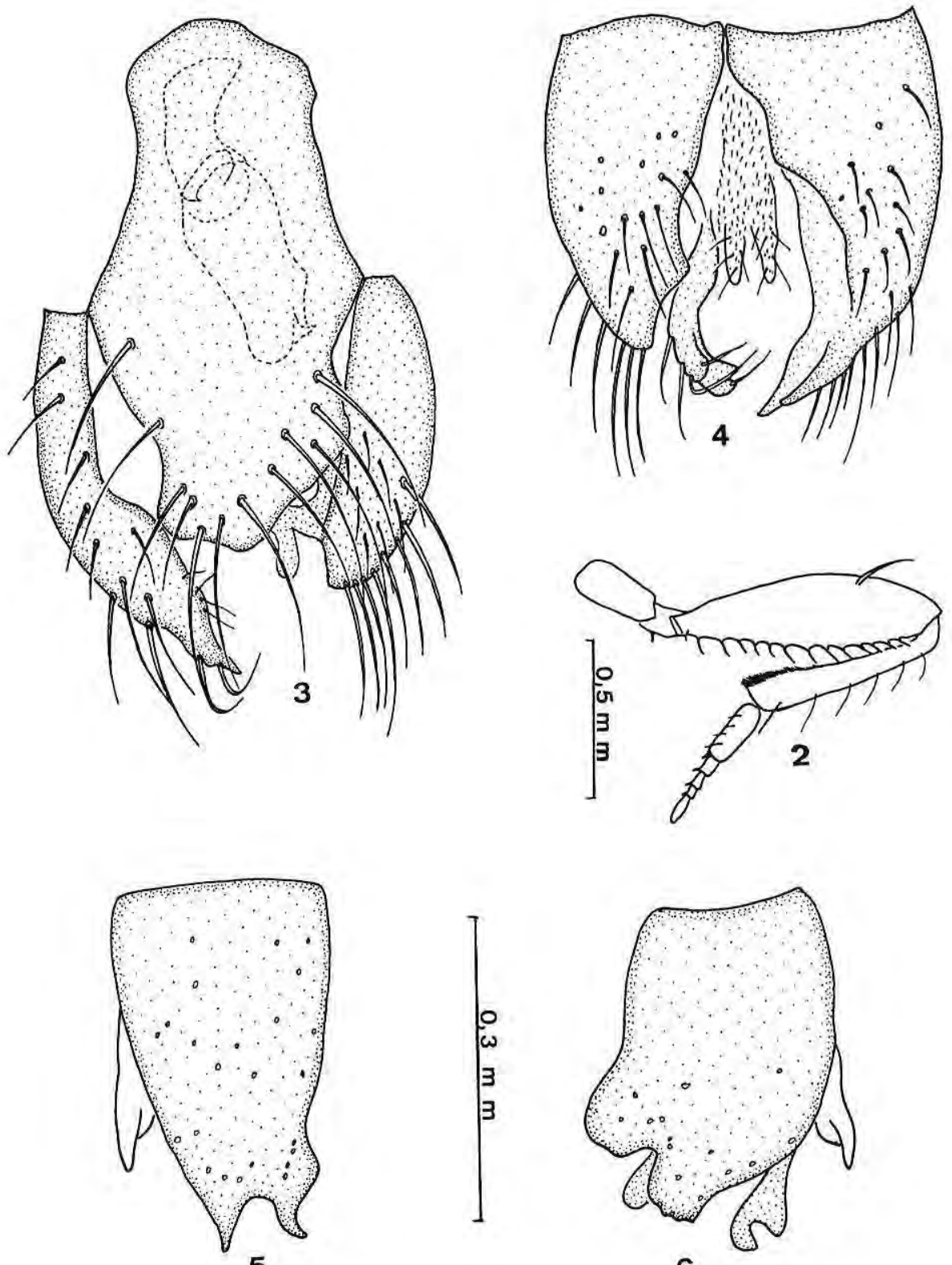

5

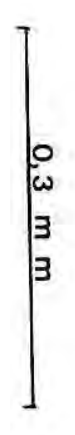

6

Figuras 2-6. Syndyas amazonica sp.n. Holótipo macho. Fig. 2, perna esquerda, face anterior; 3, terminália, epândrio e hipândrio (edeago em linha tracejada), vista ventral; 4 , epândrio, vista dorsal; 5 , lamela epandrial direita, vista lateral; 6, lamela epandrial esquerda, vista lateral;. Figuras 3-6 na mesma escala. 
Abdome alongado, delgado, cilíndrico, preto. Todos os tergitos com pruina castanha densa no dorso e pruina azulada esparsa nas laterais; tergitos com cerdas curtas exceto tergitos 1-3 com cerdas laterais mais longas. Esternitos com cerdas longas.

Terminália assimétrica (Fig.3). Epândrio dividido dorsalmente (Fig.4); lamela epandrial direita mais longa que a esquerda (Figs.5,6); surstilo esquerdo projetando-se da margem dorsal da lamela epandrial na altura dos cercos. Hipândrio inteiro distalmente, com cerdas longas na margem distal (Fig.3). Edeago curto e robusto com apódema ejaculador ventral longo e dorsal curto, fortemente esclerotinizados.

Fêmea: desconhecida.

Registro geográfico: Brasil (Amazonas).

Material examinado: BRASIL, Amazonas, Manaus, AM $010 \mathrm{Km} \mathrm{54,}$ BI2, $02{ }^{\prime \prime} 45^{\prime} 33^{\circ} \mathrm{S}, 59^{\prime \prime} 51^{\prime} 03^{\circ} \mathrm{W}, 22-$ 02.vi.1997, Ferreira, Henriques e Vidal cols., Armadilha Suspensa, $15 \mathrm{~m}$ (holótipo macho, INPA). Condições do holótipo: terminália dissecada; asa direita montada em microlâminas.

Etimologia: o nome específico refere-se a região onde foi coletado o espécime.

\section{DISCUSSÃO}

O gênero Syndyas Loew e o gênero Lactistomyia Melander formam um grupo indubitavelmente monofilético com base nos seguintes caracteres derivados: palpifer largo com a margem inferior dobrada para dentro; face longa e estreita; surstilos articulados; cerda propleural ausente. $\mathrm{O}$ gênero Lactistomyia é exclusivamente neotropical e Syndyas, até o presente trabalho, registrado em todas as regiões zoogeográficas exceto a neotropical. Syndyas sempre foi facilmente distinguido de Lactistomyia devido a asa com áreas basais sem microtriquias, veia M ausente, tibia posterior clavada e primeiro tarsômero posterior dilatado. Entretanto, o exame de vários exemplares de Syndyas da região Afrotropical revelou que esses carateres são muito discretos em algumas espécies africanas onde a veia M é fraca, mas ainda distinta, a tíbia posterior é apenas discretamente alargada apicalmente e o primeiro tarsômero fracamente dilatado (S. amazonica sp.n. apresenta a tíbia e o primeiro tarsômero posterior também discretamente modificados). Além disso, a revisão das espécies de Lactistomyia (trabalho em preparação) revelou que algumas espécies deste gênero também apresentam áreas nuas nas asas e que este não é um caráter exclusivo de Syndyas. Com esses novos dados tornou-se necessária uma nova interpretação desses caracteres e a descoberta de outros para uma melhor definição de Syndyas e sua distinção de Lactistomyia. O gênero Syndyas pode ser distinguido de Lactistomyia com base nos seguintes caracteres (os caracteres referentes a Lactistomyia entre parênteses): cerdas da série póstero-ventral do fềmur posterior reduzidas ou ausentes (desenvolvidas); tibia posterior com face ventral arredondada, clavada apicalmente (frequentemente falciforme com face ventral afilada, se arredondada, a tíbia nunca é clavada apicalmente); primeiro tarsômero posterior dilatado, mais curto que os segmentos restantes juntos (primeiro 
tarsômero posterior deIgado, tão ou mais longo que os segmento restantes juntos); veia $\mathrm{M}$ fraca ou ausente (forte); asa hialina ou uniformemente enfuscada (hialina a castanha, frequentemente com base mais escura); célula dm curta (longa); base da veia Rs reta, geralmente atingindo a $\mathrm{R} 1$ em ângulo reto (base da Rs curva, nunca atingindo a R1 em ângulo reto); insetos pequenos, medindo de 2,5 a 3,5 (insetos maiores, raramente medindo menos de 5,0 $\mathrm{mm}$ ).

Quatro exemplares fêmeas de Syndyas de outras localidades da região amazônica foram encontrados na coleção de invertebrados do INPA, mas nenhum deles pôde ser associado com alguma segurança ao macho de S_amazonica sp.n. São provavelmente espécies diferentes, as quais serão descritas posteriormente após a devida associação aos respectivos machos. Estes exemplares apresentam em comum com Syndyas amazonica_sp.n. a célula br mais longa que a bm devido ao deslocamento da veia $\mathrm{r}-\mathrm{m}$ para mais distante da base da R4+5, portanto, uma sinapomorfia das espécies de Syndyas da Região Neotropical. São eles: BRASIL, Amazonas, Manaus, Reserva Ducke, 31.viii.1982, J.A.Rafael col., Armadilha de Malaise (1 fềmea, INPA); vi.1995, EMT.5 (1 fềmea, INPA); Novo Airão, Rio Jaú, Meriti, 04-10.vi.1994, J.A.Rafael col. (1 fêmea INPA); Pará, Benevides, F. Morelandia, 14.xi.1986, J.A.Rafael col., Armadilha de Malaise (1 fềmea, INPA).

\section{Bibliografia citada}

Chavála, M. 1983. The Empidoidea (Diptera) of Fennoscandia and Denmark. II. General Part. The families Hybotidae, Atelestidae and Microphoridae. Fauna ent, scand., 12:1-279.

Chavála, M.; Kovalev, V.G. 1988. Family Hybotidae, pp: 174-227. In: Soós, A. \& L.Papp (eds.). Catalogue of Palaearctic Diptera. Akademiai Kiadó/Bidapest. Vol.6, 435pp.

Cumming, J.M.; Sinclair, B.J.; Wood, D.M. 1995. Homology and phylogenetic implications of the male genitalia in Diptera Eremoneura. Ent. Scan.,26:121-152.

McAlpine, J.F. 1981. Morphology and terminology, pp:9-63, In: J.F.McAlpine et al (eds.) Manual of Nearctic Diptera v.1, Ottawa, Res. Branch. Agriculture Canada, 674p.

Smith, K.G.V. 1977. Family Empididae (Empidae, Hybotidae), pp:185-211. In: Delfinado, M.D. \& D.E.Hardy (eds.). $A$ catalogue of the Diptera of the Oriental Region. Vol. II. Suborder Brachycera through Division Aschiza, suborder Cyclorrapha. Univ. Press. of Hawaii, Honolulu, 459 pp.

Smith, K.G.V. 1980. Family Empididae, pp:431422. In: Crosskey, R.W. (ed.). Catalogue of the Diptera of the Afrotropical Region. British Museum (Nat. Hist.), London 1435 pp.

Smith, K.G.V. 1989. Family Empididae, pp:382392. In: Evenhuis, N.L. (ed.). Catalog of the Diptera of the Australasian and Oceanian Regions. Bishop Museum Press - Brill, 1155pp.

Teskey, H.J.; Chillcott, J.G. 1977. A revision of the nearctic species of Syndyas Loew (Diptera: Empididae). Can. Ent., 109:1445-1455. 